\title{
Endovascular comprehensive stroke center designation parameters
}

Nazli Janjua, MD

Irene Katzan, MD

Aamir Badruddin, MD

Thanh N. Nguyen, MD

Alex Abou-Chebl, MD

Osama O. Zaidat, MD, MS

Correspondence \& reprint requests to Dr. Janjua: nazli.janjua@apcsi.org

Neurology ${ }^{\circledR}$ 2012;79 (Suppl 1):S239-S242
The approval of IV tissue plasminogen activator (IV tPA), ${ }^{1}$ the first stroke revascularization therapy, limiting ischemia in progress, led to the establishment of criteria to define primary stroke centers (PSCs), ${ }^{2} \mathrm{ca}-$ pable of delivering this treatment. Corollary to PSC designation, the establishment of stroke units, comprising nursing and physician personnel trained in the care of stroke patients, improves outcome for stroke patients. ${ }^{3-7}$ The market approval of various novel devices aimed at removing thrombus from occluded blood vessels in the setting of acute ischemic stroke (AIS) ${ }^{8,9}$ and the recognition of these as a potential treatment option for certain patients has helped spur the development of recommendations and metric standards for comprehensive stroke centers (CSCs) by the Brain Attack Coalition (BAC), and endorsement by the Society of Vascular and Interventional Neurology (SVIN). ${ }^{10,11}$ Additionally, the evolution of the neurocritical care discipline over the past 2 decades, with specialized care for AIS and hemorrhagic stroke, including subarachnoid and intracranial hemorrhage, is considered as an optional component in the proposed metrics criteria for CSCs (table).

Many proposed components of CSCs include infrastructure also necessary for PSC function: "acute stroke teams, written care protocols ... [and an] integrated emergency response system." In addition, basic services required for care of stroke patients remain core requirements for both PSCs and CSCs: "availability and interpretation of CT scans 24 hours ... and rapid laboratory testing, administrative support, strong leadership, and continuing education." $2 \mathrm{Be}-$ yond these elements, CSCs may be further distinguished by the availability of "vascular neurosurgery and neurology; advanced neuroimaging capabilities such as MRI and various types of cerebral angiography; surgical and endovascular techniques, including clipping and coiling of intracranial aneurysms, carotid endarterectomy, and intra-arterial thrombolytic therapy." ${ }^{10}$ Optional components for CSCs include neuroscience intensive care units (neuro-ICUs), perfusion imaging techniques, and other (laboratory and research) personnel.

The designation of PSCs creates an infrastructure for the improved delivery of hyperacute therapy. In addition, it aids emergency medical services (EMS) in identifying appropriate acute stroke facilities for patient transport and improves dialogue and collaborations between EMS and hospitals. PSC-designated facilities must also hold at least biannual community education events, thereby having direct public impact. ${ }^{2}$ Quality review processes to assess ongoing performance, also required for designated CSCs, further enhance centers' ability to continually reassess their delivery of stroke care at a high standard. Success of the system is manifested in increased rates of IV tPA utilization in the United States; for example, in Michigan the rate increased by $50 \%$ (to $4.6 \%$, from $3 \%$ ), ${ }^{12}$ and in New York the rate doubled (to $5.2 \%$, from $2.4 \%)^{13}$ after the certification process began for PSCs. Also, 33\% of patients were evaluated by a stroke or rapid response team at certified centers, vs $0.4 \%$ at noncertified centers. ${ }^{12}$ Furthermore, whereas many stroke treatments have failed to demonstrate improvements in mortality rates, ${ }^{1}$ care of patients in stroke centers has. ${ }^{14}$

Ideally, the formation of CSCs would have the same effect on the delivery of endovascular recanalization therapy (ERT), by improving institutional support for endovascular services and aiding implementation of a systems-based approach to stroke care with regional transport protocols.

There are important practical issues involved in patient transport to CSCs, and these create considerable debate among stakeholders in the CSC certification process. These issues may relate to loss of reimbursement and revenues for hospitals that may be capable of providing PSC level care but not ERT. More important, the greater distance between the patient's origin and final hospital increases the time to arrival at the tertiary stroke hospital, which could de-

From Asia Pacific Comprehensive Stroke Institute (N.J.), Pahoa, HI; Department of Neurology (I.K.), Cleveland Clinic Foundation, Cleveland, OH; Department of Neurosurgery (A.B.), University of Illinois at Chicago, Chicago; Department of Neurology (T.N.N.), Boston Medical Center, Boston, MA; Department of Neurology (A.A.-C.), University of Louisville, Louisville, KY; and Departments of Neurology, Neurosurgery, and Radiology (O.O.Z.), Medical College of Wisconsin, Milwaukee.

Go to Neurology.org for full disclosures. Disclosures deemed relevant by the authors, if any, are provided at the end of this article. 


\begin{tabular}{|c|c|c|c|}
\hline Table & \multicolumn{3}{|c|}{$\begin{array}{l}\text { Primary vs comprehensive stroke center } \\
\text { requirements }{ }^{\mathrm{a}} \text { and optional elements }\end{array}$} \\
\hline \multicolumn{2}{|c|}{ Element } & PSC & $\csc$ \\
\hline \multicolumn{2}{|c|}{ Neurologic availability } & Optional & Required \\
\hline \multicolumn{2}{|c|}{ Neurosurgical availability } & Required $^{b}$ & Required \\
\hline \multicolumn{2}{|c|}{ Vascular surgery } & ND & Required \\
\hline \multicolumn{2}{|c|}{ Stroke team } & Required & Required \\
\hline \multicolumn{2}{|c|}{ Neurointerventional capabilities } & ND & Required \\
\hline \multicolumn{2}{|c|}{ Advanced practice nurse } & ND & Required \\
\hline \multicolumn{2}{|c|}{ Written care protocols } & Required & Required \\
\hline \multicolumn{2}{|c|}{ Emergency department } & Required & ND \\
\hline \multicolumn{4}{|c|}{ Intensive care unit } \\
\hline \multicolumn{2}{|c|}{ Stroke unit } & Optional $^{\mathrm{c}}$ & Required \\
\hline \multicolumn{2}{|c|}{ Neurocritical care unit } & Optional & Optional \\
\hline \multicolumn{2}{|c|}{ Neuroimaging $^{d}$} & Required & Required \\
\hline \multicolumn{2}{|c|}{ Perfusion imaging } & ND & Optional \\
\hline \multicolumn{2}{|c|}{ Rehabilitation therapy } & ND & Required \\
\hline \multicolumn{2}{|c|}{ Speech/swallow assessment } & ND & Required \\
\hline
\end{tabular}

Abbreviations: $\mathrm{CSC}=$ comprehensive stroke center; ND = not discussed in recommendations for PSCs or CSCs; $\mathrm{PSC}=$ primary stroke center.

a Some requirements of PSCs and CSCs, as proposed by Alberts et al.2,10 (see text also).

${ }^{b}$ On-site neurosurgical service not required, but neurosurgical services should be available to patients within 2 hours either on-site or by transfer to another hospital.

${ }^{\mathrm{c}}$ Required only for those hospitals providing ongoing stroke care after initial emergency department treatment.

${ }^{d}$ Cranial CT or MRI available within 25 minutes for acute stroke patients, 24 hours/day.

lay the initiation of therapy. This expends sometimes limited EMS resources and also places burdens on families who must accompany patients to distant hospitals for extended periods of time. Currently, there is Class I, Level B evidence for consideration of endovascular treatment for ruptured intracranial aneurysms and intra-arterial thrombolysis for select patients. ${ }^{15,16}$ Additional studies would likely increase the acceptance of ERT for AIS. Although there is understanding among the neurovascular and neurointerventional community that additional data on ERT are needed, even IV tPA, the current standard of care, has not demonstrated lower mortality, an important outcome. ${ }^{1}$ Despite limited data for ERT in AIS, IV tPA may be less effective in recanalizing large artery occlusion (LAO). ${ }^{17,18}$ Furthermore, even though designation of PSCs has helped increase utilization of IV tPA, its administration is still limited to a minority of the population, ${ }^{12,13}$ thus limiting its overall impact on stroke morbidity. ERT may potentially have additional effect on this. In patients with suspected LAO transferred for ERT, delays in transfer reduce the number of patients ultimately offered catheter-based intervention. ${ }^{19}$
Other optional proposed CSC components may be difficult to achieve for even tertiary centers. The nationwide shortage of neurointensivists, who may have a positive impact on discharge disposition and outcome of critically ill patients with ischemic stroke, ${ }^{20,21}$ is demonstrated by the fact that many hospitals lack dedicated neuro-ICUs (which have been linked to higher rates of aneurysm-specific treatment and discharge to home among subarachnoid hemorrhage patients ${ }^{22}$ ), though they are fully capable of providing round-the-clock endovascular ischemic or hemorrhagic stroke treatment. This may create a need for additional interfacility arrangements such as "drip-and-ship" or "clip-and-ship" to a hospital where a dedicated neuro-ICU, certified neurointensivists, certified vascular neurologists, and neurosurgeons are available. And just as delayed transfer of patients with stroke negatively impacts possible endovascular treatment, stays in emergency departments for longer than 5 hours for neuro-ICU-bound patients have been linked to poor outcome in retrospective studies. ${ }^{23}$

Various stakeholders directly or indirectly further the advancement of stroke center designation. Professional societies, as mentioned above, evaluate the data and literature and provide guidelines for stroke centers. Industries that manufacture medications and devices used in the treatment of patients with stroke often partner with hospitals, physicians, scientists, and granting agencies to provide community education and support registries to collect data on treatments for stroke. ${ }^{24-27}$ Ultimately, the judicious evaluation of such data must be performed by nonpartisan experts within the context of randomized clinical trials, with operator-independent adjudication of outcome measures. Professional organizations, such as SVIN, the American Academy of Neurology, and American Heart/American Stroke Association, must partner with the NIH/National Institute for Neurological Disorders and Stroke, private industry, and the US Food and Drug Administration to rigorously evaluate new therapies.

If future studies establish firm benefit of ERT for patients with AIS, then the implementation of CSCs will be indispensible to optimize its use in acute stroke management. The CSC certification process would aid EMS in the identification of facilities capable of performing ERT, as well as aid neurologists, emergency physicians, primary care physicians, and the community at large in identifying comprehensive stroke centers of excellence. Emergency medical services will then be charged with the task of transporting stroke victims to the most appropriate nearest facility. Additionally, CSCs should help shape and organize regional approaches to the transport of patients with acute stroke. Streamlined hospital-tohospital transfer protocols should be developed and 
continually refined to minimize delays. When patients arrive at a CSC, treatment protocols and algorithms can make acute stroke care expedient, with increased quality of services provided. Complete or limited telestroke consultation, with online access to imaging studies, electrocardiographs, and laboratory studies from the referring hospital, can help the stroke and endovascular teams at the recipient hospital assess baseline neuroimaging studies and become more efficient in their evaluation of the patient.

The development of CSC certification represents a powerful opportunity to increase the availability of ERT for patients with acute stroke and create expeditious arrangements between hospitals to facilitate sharing of limited resources, to the benefit of the public. The process will raise important policy and monetary issues. The initial metric paper of the BAC provides a framework for CSCs. However, greater and more detailed standards, such as "times to groin," for ERT, analogous to "times to needle" for IV tPA, must be established (see companion article in this supplement, p. S243).

The collective societies representing vascular neurologists, neurointensivists, neurointerventionalists, and neurosurgeons must be ready to actively engage in these important discussions.

\section{AUTHOR CONTRIBUTIONS}

Dr. Janjua: drafting/revising the manuscript, study concept or design. Dr. Katzan: drafting/revising the manuscript. Dr. Badruddin: drafting/revising the manuscript. Dr. Nguyen: drafting/revising the manuscript. Dr. Abou-Chebl: drafting/revising the manuscript. Dr. Zaidat: drafting/ revising the manuscript, study concept or design, analysis or interpretation of data, study supervision.

\section{DISCLOSURE}

Dr. Janjua was reimbursed for airfare and hotel expense to attend the roundtable SVIN Summit and performs intra-arterial stroke procedures. Dr. Katzan has served as a consultant for Genentech, Inc., for the development of an EMS education tool for acute stroke, receives research support from Ohio Department of Health, and is lead physician for the Ohio Paul Coverdell Stroke Registry. Dr. Badruddin reports no disclosures. Dr. Nguyen has served as an Associate Editor of Frontiers of Vascular and Interventional Neurology and Editor of SVIN Newsletter. Dr. Nguyen performs intra-arterial stroke procedures. Dr. Abou-Chebl serves on the advisory boards for Focal Cool Inc. and Arterain Medical Inc.; has served on the editorial advisory board for Stroke and Frontiers in Neurology; served on the speakers bureau for BMS/Sanofi Partnership; performs cerebral angiography and intra-arterial thrombolysis procedures; and holds stock options in Focal Cool Inc. and Arterain Medical Inc. Dr. Zaidat serves on the scientific advisory board for Talecris; served on the adjudication committee for Stryker; received speaker honoraria from Stryker; served on the editorial board of Frontiers in Neurology (Endovascular \& Interventional Neurology Section); serves as Editor of The Journal of Neurointerventional Surgery; and serves as Associate Editor and is a member of the editorial board of Journal of Stroke \& Cerebrovascular Diseases; served as a consultant for Stryker Neurovascular-Commercial, Codman NeurovascularCommercial, and Microvention Inc.-Commercial; and has received research support from a Society of Vascular \& Interventional Neurology (SVIN) grant for this educational activity. Go to Neurology.org for full disclosures.

Received August 24, 2011. Accepted in final form October 17, 2011.

\section{REFERENCES}

1. The National Institute of Neurological Disorders and Stroke rt-PA Stroke Study Group. Tissue plasminogen activator for acute ischemic stroke. N Engl J Med 1995;333: 1581-1587.

2. Alberts MJ, Hademenos G, Latchaw RE, et al. Recommendations for the establishment of primary stroke centers: brain attack coalition. JAMA 2000;283:3102-3109.

3. Candelise L, Gattinoni M, Bersano A, Micieli G, Sterzi R, Morabito A. Stroke-unit care for acute stroke patients: an observational follow-up study. Lancet 2007;369:299-305.

4. Strand T, Asplund K, Eriksson S, Hagg E, Lithner F, Wester PO. A non-intensive stroke unit reduces functional disability and the need for long-term hospitalization. Stroke 1985;16:29-34.

5. Jorgensen HS, Nakayama H, Raaschou HO, Larsen K, Hubbe P, Olsen TS. The effect of a stroke unit: reductions in mortality, discharge rate to nursing home, length of hospital stay, and cost: a community-based study. Stroke 1995;26:1178-1182.

6. Indredavik B, Bakke F, Solberg R, Rokseth R, Haaheim LL, Holme I. Benefit of a stroke unit: a randomized controlled trial. Stroke 1991;22:1026-1031.

7. Zhu HF, Newcommon NN, Cooper ME, et al. Impact of a stroke unit on length of hospital stay and in-hospital case fatality. Stroke 2009;40:18-23.

8. Smith WS. Safety of mechanical thrombectomy and intravenous tissue plasminogen activator in acute ischemic stroke: results of the Multi Mechanical Embolus Removal in Cerebral Ischemia (MERCI) trial, part I. AJNR Am J Neuroradiol 2006;27:1177-1182.

9. The Penumbra Pivotal Stroke Trial Investigators. The Penumbra Pivotal Stroke Trial: safety and effectiveness of a new generation of mechanical devices for clot removal in intracranial large vessel occlusive disease. Stroke 2009;40: 2761-2768.

10. Alberts MJ, Latchaw RE, Selman WR, et al. Recommendations for comprehensive stroke centers: a consensus statement from the brain attack coalition. Stroke 2005;36: 1597-1616

11. Leifer D, Bravata DM, Connors JJ 3rd, et al. Metrics for measuring quality of care in comprehensive stroke centers: detailed follow-up to brain attack coalition comprehensive stroke center recommendations: a statement for healthcare professionals from the American Heart Association/American Stroke Association. Stroke 2011;42:849-877.

12. Rajamani K, Millis S, Watson S, et al. Thrombolysis for acute ischemic stroke in joint commission-certified and -noncertified hospitals in Michigan. J Stroke Cerebrovasc Dis Epub 2011 Aug 16.

13. Gropen TI, Gagliano PJ, Blake CA, et al. Quality improvement in acute stroke: The New York State Stroke Center Designation Project. Neurology 2006;67:88-93.

14. Xian Y, Holloway RG, Chan PS, et al. Association between stroke center hospitalization for acute ischemic stroke and mortality. JAMA 2011;305:373-380.

15. Molyneux AJ, Kerr RS, Yu LM, et al. International subarachnoid aneurysm trial (ISAT) of neurosurgical clipping versus endovascular coiling in 2143 patients with ruptured intracranial aneurysms: a randomised comparison of effects on survival, dependency, seizures, rebleeding, subgroups, and aneurysm occlusion. Lancet 2005;366:809817. 
16. Furlan A, Higashida R, Wechsler L, et al. Intra-arterial prourokinase for acute ischemic stroke: The PROACT II Study: a randomized controlled trial: Prolyse in acute cerebral thromboembolism. JAMA 1999;282:2003-2011.

17. Linfante I, Llinas RH, Selim M, et al. Clinical and vascular outcome in internal carotid artery versus middle cerebral artery occlusions after intravenous tissue plasminogen activator. Stroke 2002;33:2066-2071.

18. Christou I, Burgin WS, Alexandrov AV, Grotta JC. Arterial status after intravenous tPA therapy for ischaemic stroke: a need for further interventions. Int Angiol 2001;20:208-213.

19. Prabhakaran S, Ward E, John S, et al. Transfer delay is a major factor limiting the use of intra-arterial treatment in acute ischemic stroke. Stroke 2011;42:1626-1630.

20. Varelas PN, Schultz L, Conti M, Spanaki M, Genarrelli T, Hacein-Bey L. The impact of a neuro-intensivist on patients with stroke admitted to a neurosciences intensive care unit. Neurocrit Care 2008;9:293-299.

21. Bershad EM, Feen ES, Hernandez OH, Suri MF, Suarez JI. Impact of a specialized neurointensive care team on outcomes of critically ill acute ischemic stroke patients. Neurocrit Care 2008;9:287-292.
22. Samuels O, Webb A, Culler S, Martin K, Barrow D. Impact of a dedicated neurocritical care team in treating patients with aneurysmal subarachnoid hemorrhage. Neurocrit Care 2011;14:334-340.

23. Rincon F, Mayer SA, Rivolta J, et al. Impact of delayed transfer of critically ill stroke patients from the emergency department to the neuro-ICU. Neurocrit Care 2010;13:75-81.

24. Gray WA, Hopkins LN, Yadav S, et al. Protected carotid stenting in high-surgical-risk patients: the Archer results. J Vasc Surg 2006;44:258-268.

25. Iyer SS, White CJ, Hopkins LN, et al. Carotid artery revascularization in high-surgical-risk patients using the carotid wall stent and filterwire EX/EZ: 1-year outcomes in the beach pivotal group. J Am Coll Cardiol 2008;51:427-434.

26. Yadav JS, Wholey MH, Kuntz RE, et al. Protected carotidartery stenting versus endarterectomy in high-risk patients. N Engl J Med 2004;351:1493-1501.

27. Zaidat OO, Klucznik R, Alexander MJ, et al. The NIH registry on use of the Wingspan stent for symptomatic $70-99 \%$ intracranial arterial stenosis. Neurology 2008; $70: 1518-1524$. 


\section{Neurology}

\section{Endovascular comprehensive stroke center designation parameters}

Nazli Janjua, Irene Katzan, Aamir Badruddin, et al.

Neurology 2012;79;S239-S242

DOI 10.1212/WNL.0b013e318269599f

This information is current as of September 24, 2012

\section{Updated Information \&}

Services

References

Subspecialty Collections

Permissions \& Licensing

Reprints including high resolution figures, can be found at:

http://n.neurology.org/content/79/13_Supplement_1/S239.full

This article cites 26 articles, 11 of which you can access for free at: http://n.neurology.org/content/79/13_Supplement_1/S239.full\#ref-list1

This article, along with others on similar topics, appears in the following collection(s):

All Cerebrovascular disease/Stroke

http://n.neurology.org/cgi/collection/all_cerebrovascular_disease_strok e

All Health Services Research

http://n.neurology.org/cgi/collection/all_health_services_research

Information about reproducing this article in parts (figures,tables) or in its entirety can be found online at:

http://www.neurology.org/about/about_the_journal\#permissions

Information about ordering reprints can be found online:

http://n.neurology.org/subscribers/advertise

Neurology ${ }^{\circledR}$ is the official journal of the American Academy of Neurology. Published continuously since 1951, it is now a weekly with 48 issues per year. Copyright Copyright $@ 2012$ by AAN Enterprises, Inc.. All rights reserved. Print ISSN: 0028-3878. Online ISSN: 1526-632X.

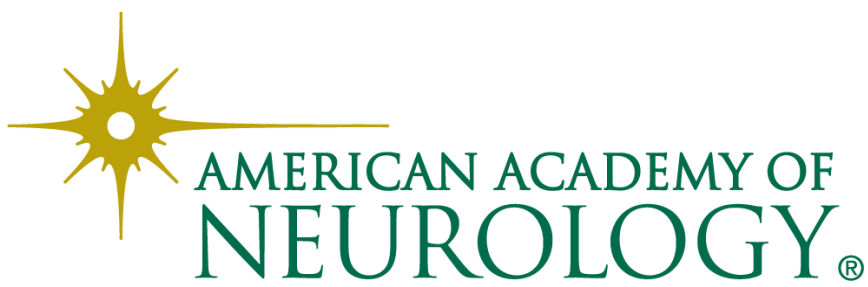

